This is the penultimate draft of a paper commissioned for the Routledge Handbook of Epistemic Contextualism, ed. J.J. Ichikawa. Taylor and Francis (2016). Please do not cite without permission.

\title{
Conversational Kinematics
}

Robin McKenna

University of Vienna

rbnmckenna@gmail.com

Abstract Contextualism is the view that knowledge ascriptions - utterances of sentences containing the word "knows" - express different propositions in different contexts of utterance. But what features of context determine the propositions expressed by knowledge ascriptions? According to a version of contextualism I call conversational contextualism, the conversational dynamics or kinematics determine the propositions expressed by knowledge ascriptions. In this paper I argue that the most sophisticated version of conversational contextualism, which is the view defended in Blome-Tillmann (2009; 2014), faces serious problems. My (very) tentative conclusion will be that conversational contextualism should be abandoned because of these problems.

\section{Introduction}

Contextualism is the view that knowledge ascriptions - utterances of sentences containing the word "knows" - express different propositions in different contexts of utterance. Consider these examples:

LOW: Hannah and Sarah are discussing whether the bank is open on Saturdays. Hannah recalls it was open on a previous Saturday. She says "I know that the bank is open on Saturdays". Sarah agrees.

HIGH: Laura and Sarah are discussing whether the same bank is open on Saturdays. Sarah says "Hannah has been in there on Saturday before". But Laura replies "Banks can change their opening hours. Hannah doesn't know that the bank is open". Sarah agrees. ${ }^{1}$

Assume the bank is open. The thought is that Hannah's knowledge ascription and Laura's knowledge denial are both true, even though we can specify that Hannah's epistemic position is the same in both cases (for dissent see Brown 2006; Nagel 2008; Rysiew 2001). The contextualist

\footnotetext{
${ }^{1}$ These are modified versions of DeRose's (1992) 'bank cases'.
} 
explanation is that their respective uses of "knows" have different semantic values. ${ }^{2}$ Let's say that an utterance of "S knows that $p$ " is true in a context c iff S's evidence rules out all of the alternatives in which not- $p$ that are relevant in $\mathrm{c}$, where different sets of alternatives are relevant in different contexts (see Blome-Tillmann 2014; Ichikawa 2011; Lewis 1996). ${ }^{3}$ The alternative in which the bank has changed its opening hours is relevant in HIGH (Laura and Sarah take it seriously), but isn't relevant in LOW (Hannah and Sarah don't consider it). So Hannah's use of “knows” refers to a property the possession of which would allow Hannah to rule out one set of alternatives, whereas Laura's use of "knows" refers to a property the possession of which would allow Hannah to rule out another set. Because (let's assume) Hannah has the former property but not the latter, Hannah's knowledge ascription is true, whereas Laura's is false. ${ }^{4}$

Contextualism says that the semantic values of uses of "knows" depend on features of the context of utterance. But what features? In other words, what makes an alternative relevant (or, an epistemic standard appropriate)? Jason Stanley (no friend of contextualism) suggests this answer:

On a standard account of context-sensitive expressions, their semantic contents, relative to a context, are determined by facts about the intentions of the speaker using that expression. On this account, the reason that a use of (for example) 'that cat' refers to a particular cat is because of the linguistic meaning of 'that cat', together with the referential intentions of the user of that expression on that occasion. Call the view that all context-sensitive expressions behave in this manner the intention-based view of context-sensitive expressions (2005: 25).

The intention-based view says that the set of relevant alternatives in a context is the set of alternatives those in the context intend to be talking about. But the contextualist need not accept this view. First, it may well be false. David Kaplan (1989a) has argued that the semantic values of uses of pure indexicals (e.g. "I") and demonstratives (e.g. "that") don't depend on referential

\footnotetext{
${ }^{2}$ Strictly speaking, this is just a contextualist explanation. Some contextualists hold that uses of "knows" refer to the same relation in all contexts, but that relation has an argument place that varies with the context of utterance. For discussion see Schaffer (2004); Schaffer and Szabo (2013).

${ }^{3}$ I use "S", " $p$ " and "c" as schematic letters for subjects, propositions and contexts respectively. ${ }^{4}$ I sometimes talk about epistemic standards, the idea being that different standards are appropriate in different contexts. For instance, a strict standard is appropriate in HIGH, whereas a laxer standard is appropriate in LOW. For discussion of the differences between 'relevant alternatives contextualism' and 'shifting standards contextualism' see Ichikawa (forthcoming); Schaffer (2005).
} 
intentions. If Catriona says "I am tired" she refers to Catriona, not whoever she intended to refer to (maybe Catriona thinks she is Laurie). If I say "that café", while pointing at Café Landtmann, I refer to Café Landtmann, not whichever café I intended to refer to (maybe I thought I was pointing at Café Central). If Kaplan is right, then the semantic values of uses of some context-sensitive expressions don't depend on referential intentions. ${ }^{5}$

Second, here's Stewart Cohen (a prominent contextualist) on the question of what determines the standards:

This is a very difficult question to answer. But we can say this much. The standards are determined by some complicated function of speaker intentions, listener expectations, presuppositions of the conversation, salience relations, etc., by what David Lewis calls the conversational score (1999: 61).

Cohen only says that speaker intentions are part of the story. Consequently, it is at best unclear whether he accepts the intention-based view. ${ }^{6}$

Cohen's picture (based on Lewis 1979) is roughly as follows. The speakers in a conversational context make various conversational moves. These moves are informed by their intentions, expectations, presuppositions and purposes. Catriona says she "knows" that the train leaves at $3 \mathrm{pm}$. Morven points out that they need to catch this train, and asks if Catriona has seen the latest timetable. Catriona says she has, and the next train is at $3 \mathrm{pm}$. Laurie suggests there might be a problem on the track, and the train won't leave until later. Catriona admits she can't rule this out. As this conversation develops, the set of relevant alternatives expands. At first, the alternative in which there is a problem on the track was irrelevant (it hadn't occurred to anyone). At the end, the alternative is relevant (everyone accepts it is worth considering). Their conversational moves determine the set of relevant alternatives. The set of relevant alternatives depends on the 'dynamics' or 'kinematics' of conversation. For want of a better label, I'll call this 'conversational contextualism'. Conversational contextualism is broader than the intention-based view.

\footnotetext{
${ }^{5}$ While most agree that "I" is a pure indexical in Kaplan's sense, it is unclear whether there are any other pure indexicals. Kaplan's account of demonstratives is controversial (see Bach 1992; King 2014; Reimer 1991), and he abandoned it (see Kaplan 1989b).

${ }^{6}$ DeRose (2009: 135-6) makes similar remarks. I discuss Blome-Tillmann (2009; 2014) and Lewis (1996) below.
} 
Conversational contextualism says that the set of relevant alternatives depends on conversational kinematics. The intention-based view says that the set depends on a particular aspect of conversational kinematics, viz. the speaker's referential intentions.

The paper has three parts. In $\$ 1$ I outline the most sophisticated version of conversational contextualism, which is the view defended in Blome-Tillmann (2009; 2014). In \$2 I argue that conversational contextualism faces serious problems. Put briefly, conversational contextualism makes it too hard to count as "knowing" in contexts where the speakers have relevant false beliefs about the epistemic situation of the subject they are evaluating. In $\$ 3$ I consider three responses to this objection. I argue that none of them are successful, so we have reason to abandon conversational contextualism. But my conclusion is not that we have reason to abandon contextualism. While the literature has focused on views that tie the set of relevant alternatives to conversational kinematics, one can be a contextualist without tying the set of relevant alternatives to conversational kinematics. I finish by briefly sketching what this kind of view might look like.

\section{Conversational Contextualism}

Our question is: what makes an alternative relevant? Lewis (1996) provides a list of rules specifying exactly when an alternative is relevant. In this section I outline Lewis's rules, and explain why Blome-Tillmann's $(2009 ; 2014)$ modified list of rules rectifies the failings of Lewis's.

Lewis gives us four rules: ${ }^{7}$

RULE OF ACTUALITY (RA): If an alternative in which not- $p$ is actual, then that alternative is relevant in c (1996: 554-5). ${ }^{8}$

RULE OF BELIEF (RB): If the subject believes (or should believe) an alternative in which not- $p$ is actual, then that alternative is relevant in c (ibid.).

\footnotetext{
${ }^{7}$ I ignore Lewis's (1996: 558-9) three 'permissive' rules of reliability, method and conservatism. They make no difference in what follows.

${ }^{8}$ Lewis means actual in the world of the subject to whom "knowledge" is ascribed, not actual in the world of the ascriber (the two come apart when "knowledge" is ascribed to counterfactual subjects). 
RULE OF RESEMBLANCE (RRE): If an alternative in which not- $p$ saliently resembles another relevant alternative (made relevant in some other way), then that alternative is relevant in c (ibid: 556-7).

RULE OF ATTENTION (RT'T): If an alternative in which not- $p$ is not ignored in $\mathrm{c}$, then that alternative is relevant in c (ibid.: 559).

Some comments are in order. RA ensures that a knowledge ascription is true only if the relevant proposition is true: "S knows that $p$ " is true only if $p$ is true. $\mathrm{RB}$ ensures that a knowledge ascription is true only if the subject doesn't (or shouldn't) believe that an alternative in which $p$ is false is actual: "S knows that $p$ " is true only if S doesn't (or shouldn't) believe that $p$ is false.

RRE is a little less clear. The basic thought is that there may be a number of respects in which an alternative resembles an alternative that is already relevant, and whether any of those respects are salient depends on the context (see ibid.: 557-66 and his discussion of 'poor Bill'). Perhaps the most serious problem with RRE is that it allows that there are contexts in which one can truly say that the subject in a Gettier case "knows" (these are contexts where the alternatives in which the Gettierised subject's belief is false don't saliently resemble actuality). ${ }^{?}$

Lewis's defence of RT'T is brief:

$[\mathrm{RTT}]$ is more a triviality than a rule. When we say that a possibility is properly ignored, we mean exactly that; we do not mean that it could bave been properly ignored. Accordingly, a possibility not ignored at all is ipso facto not properly ignored (1996: 559).

However, as Blome-Tillmann (2009; 2014: Ch. 1) has argued, RT'T should be rejected. I will outline his argument before turning to his proposed replacement for RTT. Consider this case:

TEENAGER: Laurie is lying in bed. She hears her teenage son's bedroom window open, so she gets up and looks out. She sees someone who looks a lot like her son jumping out onto the ground below. She goes into the bedroom and finds it empty. She concludes that her son has slipped out, and spends the night fuming. In fact, this is exactly what happened. In the morning she challenges him: "I know you went out

\footnotetext{
${ }^{9}$ Lewis (ibid.: 557-8) took this to be a virtue of RRE. But Brogaard (2004) and Cohen (1998) show that it is a vice.
} 
late last night. I heard you." The son responds: "How do you know? It’s possible that you dreamt the whole thing".

If the son continues to insist it's possible that Laurie dreamt the whole thing (the 'dreaming alternative'), then the dreaming alternative isn't ignored. But, if it isn't ignored, then, according to RT'T, it's relevant. Assuming Laurie can't rule the dreaming alternative out, the son speaks truly when he denies that Laurie "knows" he went out. Because this is counter-intuitive, RTT should be rejected.

TEENAGER gives us good reason to reject RT'T because it shows that RT'T makes it too hard for Laurie to count as "knowing". In order to count as "knowing" in her present context, Laurie has to somehow convince her son to ignore the dreaming alternative. But this isn't a condition Laurie should have to meet in order to count as "knowing" her son slipped out. Given the strength of her evidence, it is obvious that Laurie counts as "knowing". As I will put it in what follows, RTT is at odds with epistemological orthodoxy. While epistemologists dispute whether subjects in various real and imaginary cases can truly be said to "know" (e.g. fake barn cases), they agree that there are a number of paradigm cases in which "knowledge" can truly be ascribed. ${ }^{10}$ Our case is such a paradigm: Laurie has excellent grounds for thinking her son has slipped out, nothing funny is going on, and Laurie has no reason to think anything funny is going on. Sense perception doesn't get much (epistemically) better than this. ${ }^{11}$ So epistemological orthodoxy says that the right thing to say is that Laurie "knows" her son slipped out. ${ }^{12}$ Of course, this is not to say that this is the verdict everyone would give, much less the verdict everyone would give if they were rational. If someone had the false belief that something funny was going on - that Laurie was being tricked, say - they

\footnotetext{
${ }^{10}$ These cumbersome locutions are necessary because contextualists hold that uses of the expression "knows" refer to different properties in different contexts. Epistemologists don't have any views about the property referred to by uses of "knows" in the context of writing this paper. But they do have views about when it is right (and wrong) to ascribe "knowledge". For instance, it is wrong to ascribe "knowledge" to a subject in a Gettier case.

${ }^{11}$ If you think it does, add whatever is required.

${ }^{12}$ If the contextualist were out of the room, the defender of epistemological orthodoxy would add that the reason why it is right to say that Laurie "knows" her son slipped out is that Laurie knows her son slipped out.
} 
might deny that Laurie "knows". But epistemological orthodoxy tells us that they would be speaking falsely in doing so, albeit for understandable reasons (this point will be important in $\$ 2 .{ }^{13}$

Turning to Blome-Tillmann's account, he replaces RT'T with what he calls the 'rule of pragmatic presupposition' (RPP) (see 2009: 249-56). To understand RPP, we need the notions of 'common ground' and 'pragmatic presupposition', which Blome-Tillmann takes from Robert Stalnaker. The basic thought is that in making their conversational moves speakers often presuppose that their audience has relevant information. If I say "My wife is ill” I presuppose that my audience is aware that I have a wife. In doing so I take it to be common ground that I have a wife (I don't expect the response to be "You have a wife?"). ${ }^{14}$ Here is Stalnaker summarizing the basic idea:

$[T]$ he common ground is just common or mutual belief, and what a speaker presupposes is what she believes to be common or mutual belief. The common beliefs of the parties to a conversation are the beliefs they share, and that they recognize that they share: a proposition $[p]$ is common belief of a group of believers if and only if all in the group believe that $\varphi$, all believe that all believe it, all believe that all believe that all believe it, etc." (2002: 704).

So Stalnaker offers these characterizations of common ground and pragmatic presupposition:

COMMON GROUND: The common ground in a conversational context $\mathrm{c}$ is the body of propositions that all the conversational participants accept, all believe that all accept, all believe that all believe that all accept, and so on.

PRAGMATIC PRESUPPOSITION: A conversational participant $S$ pragmatically presupposes $p$ in $\mathrm{c}$ iff $\mathrm{S}$ believes $p$ to be common ground in c.

${ }^{13}$ Does this apply in conversational contexts where skeptical scenarios are taken seriously? This is tricky because the contextualist solution to skepticism requires that there are contexts where it can be true to say that subjects lack "knowledge" even though epistemological orthodoxy tells us that they can truly be said to "know" (see DeRose 1995). Because none of the cases I discuss involve skeptical scenarios I set this complication aside.

${ }^{14}$ Sometimes my act of saying "My wife is ill" makes it common ground that I have a wife. This phenomenon is known as presupposition accommodation. For discussion see Karttunen (1974); Lewis (1979); Stalnaker (1974). 
While Blome-Tillmann accepts this basic picture, he proposes an amendment to PRAGMATIC PRESUPPOSITION:

PRAGMATIC PRESUPPOSITION*: A conversational participant $\mathrm{S}$ pragmatically presupposes $p$ in $\mathrm{c}$ iff $\mathrm{S}$ is disposed to behave as if she believes $p$ to be common ground in c (2009: 253).

His reasons for doing so need not detain us here (for discussion see ibid. 249-56). The important point is that he uses these notions to formulate a replacement for RTT:

RULE OF PRAGMATIC PRESUPPOSITION (RPP): If an alternative in which not- $p$ is compatible with the conversational participants' pragmatic presuppositions in c, then that alternative is relevant in c (ibid.: 256).

While RPP has a lot to recommend it, two considerations are particularly important. First, it appeals to two notions - Stalnaker's notions of common ground and pragmatic presupposition - that are independently motivated. Second, it seems to deal with TEENAGER. The case can end in one of two ways. Either the son realizes Laurie won't consider the dreaming alternative, in which case he ceases to insist on it, and so is no longer disposed to behave as if he believes it to be common ground that the alternative needs to be ruled out. Or the son continues to insist Laurie dreamt it all, in which case we end up in what Stalnaker calls a 'defective context' (ibid.: 249, ff. 17). In such contexts, it is at best unclear what alternatives are relevant, and at worst indeterminate. While this may not sound like an improvement on RT'T, Blome-Tillmann argues (convincingly) that it is (ibid.: 268-72). ${ }^{15}$

There are other aspects of Blome-Tillmann's view. While he accepts RA and RB, he proposes an alternative to RRE (see 2014: Ch. 5), and he thinks we need to add some additional rules (see 2014: Ch. 3). But RPP is the core of his view. Accordingly, my criticism in $\$ 2$ will focus on RPP. While RPP provides a compelling account of the way in which the set of relevant alternatives depends on the conversational context, I will argue that it faces serious problems.

\footnotetext{
${ }^{15}$ Blome-Tillmann's response here has a lot in common with DeRose's (2009: Ch. 4) 'single scoreboard semantics'. For criticism of single scoreboard semantics see Montminy (2013).
} 


\section{Problems for Conversational Contextualism}

In this section I will argue that RPP is as much at odds with epistemological orthodoxy as RTT. I will start by presenting the argument. I will then explain why this problem is an instance of a more general problem for a certain kind of view of semantic context-sensitivity.

Consider this case:

REAL BARNS: Catriona and Sorcha are driving through a rural area. Their friend Morven has told them that there is a particularly fetching red barn in the area, so they have been looking out for it. But Catriona has just remembered that someone told them this is the dreaded fake barn county, where almost all of the barn-shaped objects are actually fake barns. However, unbeknownst to Catriona and Sorcha, this information is entirely false. Not only are there no fake barns here, there are no fake barns for hundreds of miles. Catriona and Sorcha are discussing whether Morven actually saw a red barn in light of their (mis)information. Catriona says "Morven doesn't have the skill to distinguish between real barns and all these fakes that are around here. So she doesn't know that there was a red barn".

Catriona and Sorcha aren't just disposed to behave as if Morven saw a fake barn, they believe that she saw a fake barn. Indeed, given their misleading evidence, their belief that she saw a fake barn is reasonable. So according to RPP the alternative in which Morven saw a fake barn is relevant. Because Morven can't rule it out (we can assume she lacks the required discriminatory capacities) it follows that Catriona's utterance is true.

I would submit that this is as counter-intuitive as the verdict RTT gives about TEENAGER (I briefly discuss whether it is in \$3). My diagnosis of the problem parallels my diagnosis of the problem with RTT and TEENAGER. This is a clear case in which epistemological orthodoxy says it would be right to say that Morven "knows". Her belief was formed by a perceptual process that is reliable in normal conditions, conditions are normal, and she has no reason to think anything funny is going on. Sense perception doesn't get much better. ${ }^{16}$ Again, this is not to say that this is the verdict that everyone would give, much less the verdict that everyone would give if they were rational. Given their false beliefs, the reasonable thing for Catriona to say in REAL BARNS might be that Morven

${ }^{16}$ If you think that it does, add whatever you think is needed. In particular, if you think the argument relies on reliabilism, add that Morven has whatever non-reliabilist extras are required (e.g. reflective access to grounds in virtue of which she is justified in believing there was a red barn). 
doesn't "know". But there's a difference between it being reasonable to say something and that thing being true. Epistemological orthodoxy says that Catriona speaks falsely in denying that Morven "knows". But RPP tells us she speaks truly. So RPP is also incompatible with epistemological orthodoxy.

This problem is an instance of a general problem for a certain kind of view of semantic contextsensitivity. In a recent paper Andreas Stokke \& Torfinn Huvenes (forthcoming) argue against a view they call 'information centrism'. According to information centrism, contexts can be identified with bodies of shared information that are characterized in terms of the propositional attitudes of the conversational participants (ibid.: 1-2). As Michael Glanzberg puts it, according to this view:

The context of an utterance is the collection of propositions presupposed by participants in the conversation at the point of utterance ... The expression $I$ winds up referring to the speaker because it will be common ground among participants in a conversation who is speaking at a given time, and that $I$ picks out that person (2002: 337).

To see the problem with information centrism, consider this case:

CASTOR AND POLLuX: Castor and Pollux are identical twins, and are virtually indistinguishable. In school Castor was a model student, while Pollux got into trouble and was ultimately expelled. Their parents managed to keep this event secret, and the twins changed school. After a few years, they and their parents were the only ones to know about Pollux's tainted academic history. Later in life, a series of physical accidents and psychological complications arose, and as a result people got the identities of the twins mixed up so that everyone, including themselves, came to believe that Castor is Pollux, and that Pollux is Castor. One day, sitting in a café with some friends, Castor feels the urge to come clean, and after taking a deep breath, says "I was expelled from school” (Huvenes \& Stokke forthcoming: 4).

Huvenes and Stokke think that it is intuitive that Castor's use of "I" refers to Castor, not Pollux. So his utterance is false. But, because it is common ground that the speaker is Pollux, information centrism says that Castor's use of "I" refers to Pollux. The problem with information centrism is that it ties the semantic values of uses of context-sensitive expressions to the common ground, but 
the common ground can contain relevant false propositions (here, that the speaker is Pollux). ${ }^{17}$ As we have seen, the problem with RPP is it ties the relevance of alternatives to pragmatic presuppositions and the common ground, but the conversational participants can pragmatically presuppose relevant false propositions (here, that Morven saw a fake barn, because she's in fake barn county). So the problem is caused by the same structural feature. The problem with RPP is an instance of a more general problem for views of semantic context-sensitivity that tie the semantic values of uses of context-sensitive expressions to features of the conversational context (common ground, pragmatic presuppositions) that can contain relevant false propositions. ${ }^{18}$

\section{Possible Responses}

In this section I will canvass three responses to my argument against RPP and conversational contextualism. My tentative conclusion will be that the responses can be dealt with, and so the argument stands. I finish by briefly adverting to a different sort of contextualism

First, I have been arguing against RPP, not conversational contextualism. Why can't the conversational contextualist propose a replacement for RPP that deals with REAL BARNS? The onus is on the conversational contextualist to provide the replacement, and I am not optimistic about her prospects. Here's why. Conversational contextualists hold that an alternative being relevant is a matter of it being appropriately related to things like the common ground, speaker intentions, expectations, and pragmatic presuppositions. The problem with tying the relevance of alternatives to the common ground is that the common ground reflects the speakers' possibly false beliefs about what the world is like. Because it reflects their possibly false beliefs, the common ground can contain false propositions. Catriona and Sorcha deny that Morven "knows" because they falsely believe that she is in a fake barn case. But speaker intentions, expectations and pragmatic presuppositions also

\footnotetext{
${ }^{17}$ Can other views avoid the problem? Bach (1992) argues that views on which the semantic values of uses of context-sensitive expressions depend on referential intentions can. I lack the space to consider this more general issue here.

${ }^{18} \mathrm{I}$ have been talking as if the context of utterance entirely determines the set of relevant alternatives. But, as Ichikawa (forthcoming: Ch. 1) emphasises, the set of relevant alternatives depends on facts about the subject's circumstances as well as the context of utterance. While this complicates the objection developed in this section, I doubt it makes a difference. The objection just requires that satisfying RPP is sufficient for an alternative to be relevant.
} 
reflect the speakers' possibly false beliefs about the world. So it is unlikely that conversational contextualism can be salvaged by replacing RPP.

Second, one might deny that RPP's verdict in REAL BARNS is counter-intuitive. Whether the verdict is generally regarded as counter-intuitive is an empirical matter, which I won't speculate about here. Instead, I want to emphasise that RPP and RTT suffer from a common problem: both are incompatible with epistemological orthodoxy. My argument was not (just) that it is counter-intuitive to say that Catriona speaks truly when she denies that Morven "knows". The deeper diagnosis was that epistemological orthodoxy rules that it is wrong to deny that Morven "knows". But this was also the deeper diagnosis of what goes wrong with RTT in TEENAGER. What we need is an argument that the way in which RTT goes against orthodoxy is problematic, whereas the way in which RPP goes against orthodoxy isn't.

One might be tempted to point out the obvious difference between REAL BARNS and TEENAGER. REAL BARNS exploits the fact that RPP allows false but reasonable beliefs to affect which alternatives are relevant. TEENAGER exploits the fact that RTT allows uncooperative conversational partners to affect which alternatives are relevant. Perhaps the latter is problematic, whereas the former isn't. ${ }^{19}$ However, it isn't hard to construct variants on REAL BARNS where the conversational participants are uncooperative:

CONSPIRACY: As before, except that Catriona and Sorcha have managed to convince themselves that the government has secretly been replacing real barns in the area with fake barns. But, not only is there no such conspiracy, they have no actual evidence that this is going on. They are both just inclined to believe any conspiracy theory they come across. Catriona says "Morven thinks she saw a red barn, but we know better. There's this massive conspiracy going on. She doesn't know that there was a red barn".

Here, both Catriona and Sorcha are behaving in an epistemically uncooperative way. Because of this, RPP rules that the alternative in which Morven saw a fake barn is relevant.

\footnotetext{
${ }^{19}$ Perhaps the former is problematic too. Maybe the set of relevant alternatives depends on what epistemic standards the conversational participants would use if they were better informed, or something like that. I defend a view like this in McKenna (2014), but the view I defend is not a variety of conversational contextualism.
} 
Ultimately, I suspect that arbitrating this dispute requires getting clear on the extent to which a semantic view of a natural language expression like "knows" is beholden to the philosophical theorist's view of the extension of that expression (and vice versa). If the epistemologist says that it is right to say that a subject "knows", is it a problem for the contextualist if she has to hold that there are contexts in which it would be true to say that the subject doesn't "know"? It doesn't necessarily have to be. Just think of the contextualist solution to scepticism, according to which there are contexts in which it would be true to deny that we "know" much, if anything (see DeRose 1995). But the contextualist offers this as a solution to a deep epistemological problem. What deep epistemological problem is solved by holding that there are contexts in which it is true to deny that Morven "knows"?

Third, one might deny that the contextualist has to give rules stating when an alternative is relevant. Ichikawa (2011) gives a nice statement of this view:

"[M[any metasemantic questions about the role of context in picking out a modal base for knowledge attributions remain here unanswered. Some philosophers will be dissatisfied for this reason. In my view, such philosophers are demanding too much at once. To understand knowledge attributions as contextsensitive on the model of quantifiers, and to show that they shift in the same sorts of ways, is a substantive and interesting philosophical conclusion. Of course questions remain unanswered; these questions have unanswered analogues for quantifiers, as I've repeatedly emphasized in this paper. Such considerations, therefore, do not undermine the contextualist approach to knowledge, any more than they undermine the widely accepted contextualist approach to quantifier domains (ibid.: 398).

There is much that I agree with here. It would be a mistake to argue that contextualism is false on the basis of cases like REAL BARNS. After all, nobody would argue that "I" isn't context-sensitive on the basis of cases like CASTOR AND POLLUX. But my aim is not to argue that contextualism is false. My aim is to argue that the best contextualist view should not advert to features of conversational kinematics. So the burden is on me to suggest what an alternative account might look like.

The contextualist says that the semantic values of uses of "knows" depend on the context. The problem is to specify the features of context on which they depend. In trying to answer this question we might profit from looking at some of the broader literature. While discussions of contextualism in epistemology have focused on a particular view defended by the likes of Blome-Tillmann, Cohen, 
DeRose, Ichikawa and Lewis, there are other views on which epistemic properties and/or epistemic vocabulary depend on contexts. Take, for instance, Helen Longino's 'critical contextual empiricism', on which some content $\mathrm{A}$ which is accepted by a community $\mathrm{C}$ is knowledge for $\mathrm{C}$ just in case $\mathrm{A}$ accurately represents its intended object, is supported by the data available to $\mathrm{C}$ and has survived critical scrutiny from as many perspectives as are available in C (2002: 135-6). One could give this view a semantic spin: uses of "knows" refer to a property the possession of which requires one to be in a position to satisfy certain norms. One counts as "knowing" something (e.g. a scientific theory) only if one can show that it is supported by the available data and survives critical scrutiny from as wide a variety of perspectives are available. Because different data and perspectives will be available in different communities, what these norms require of one depends on and varies with the context. While there are issues with her story (see Longino 2002: 145-65; Rolin 2011), Longino offers a clear and compelling answer to our basic question: we can characterize contexts in terms of various norms. We must meet these norms in order to count as "knowing". Because what we need to do to meet the norms depends on the context, whether we count as "knowing" depends on the context too.

\section{Conclusion}

Conversational contextualism is the view that the semantic values of uses of the expression "knows" depend on conversational kinematics. In this paper I have argued against a particular version of conversational contextualism, on which an alternative is relevant in a context if it is compatible with the common ground in that context. Much like Lewis's RTT, this view conflicts with epistemological orthodoxy. While I haven't made a conclusive case against conversational contextualism, I hope this paper provides ample motivation for considering alternative ways of thinking about contextualism. ${ }^{20}$

\section{Bibliography}

Bach, Kent (1992). Paving the Road to Reference. Philosophical Studies 67 (3): 295-300.

Blome-Tillmann, Michael (2009). Knowledge and Presuppositions. Mind 118 (470): 241-94.

_ (2014). Knowledge and Presuppositions. Oxford: Oxford University Press.

\footnotetext{
${ }^{20}$ Thanks to Michael Blome-Tillmann, J. Adam Carter, Michael Hannon, Torfinn Huvenes and Jonathan Jenkins Ichikawa for comments on an earlier version of this paper. Research on this paper was assisted by funding from the ERC Advanced Grant Project "The Emergence of Relativism" (Grant No. 339382)
} 
Brogaard, Berit (2004). Contextualism, Skepticism, and the Gettier Problem. Synthese 139 (3): 367-86.

Brown, Jessica (2006). Contextualism and Warranted Assertibility Manoeuvres. Philosophical Studies 130 (3): 407-35.

Cohen, Stewart (1998). Contextualist Solutions to Epistemological Problems: Scepticism, Gettier, and the Lottery. Australasian Journal of Philosophy 76 (2): 289-306.

_ (1999). Contextualism, Skepticism, and the Structure of Reasons. Philosophical Perspectives 13: 57 89.

DeRose, Keith (1992). Contextualism and Knowledge Attributions. Philosophy and Phenomenological Research 52 (4): 913-29. (1995). Solving the Skeptical Problem. Philosophical Review 104 (1): 1-52. (2009). The Case for Contextualism: Knowledge, Skepticism, and Context. Oxford: Oxford University Press.

Glanzberg, Michael. (2002). Context and Discourse. Mind and Language 17 (4): 333-75.

Huvenes, Torfinn \& Andreas Stokke (Forthcoming). Information Centrism and the Nature of Contexts. Australasian Journal of Philosophy.

Ichikawa, Jonathan Jenkins (2011). Quantifiers and Epistemic Contextualism. Philosophical Studies 155 (3): 383-98. (forthcoming). Knowledge in Theory and Context. Oxford: Oxford University Press.

Kaplan, David (1989a). Demonstratives. In Joseph Almog, John Perry \& Howard Wettstein (eds.), Themes from Kaplan. New York: Oxford University Press: 481-563.

_ (1989b). Afterthoughts. In Joseph Almog, John Perry and Howard Wettstein (eds.), Themes from Kaplan. New York: Oxford University Press: 565-614.

Karttunen, Lauri. (1974). Presuppositions and Linguistic Context. Theoretical Linguistics 1: 181-94.

King, Jeffrey (2014). Speaker Intentions in Context. Noûs 48 (2): 219-37.

Lewis, David (1979). Scorekeeping in a Language Game. Journal of Philosophical Logic 8 (1): 339-59. (1996). Elusive Knowledge. Australasian Journal of Philosophy 74 (4): 549-67.

Longino, Helen (2002). The Fate of Knowledge. Princeton, NJ: Princeton University Press.

McKenna, Robin (2014). Normative Scorekeeping. Synthese 191 (3): 607-25.

Montminy, Martin (2013). The Role of Context in Contextualism. Synthese 190 (12): 2341-66. 
Nagel, Jennifer (2008). Knowledge Ascriptions and the Psychological Consequences of Changing Stakes. Australasian Journal of Philosophy 86 (2): 279-94.

Reimer, Marga (1991). Demonstratives, Demonstrations, and Demonstrata. Philosophical Studies 63 (2): 187-202.

Rolin, Kristina (2011). Contextualism in Feminist Epistemology and Philosophy of Science. In Heidi Grasswick (ed.), Feminist Epistemology and Philosophy of Science. Springer, Dordrecht: 25-44.

Rysiew, Patrick (2001). The Context-Sensitivity of Knowledge Attributions. Noûs 35 (4): 477-514.

Schaffer, Jonathan \& Zoltán Gendler Szabó (2013). Epistemic Comparativism: A Contextualist Semantics for Knowledge Ascriptions. Philosophical Studies (2): 1-53.

Schaffer, Jonathan (2004). From Contextualism to Contrastivism. Philosophical Studies 119 (1-2): 73104.

_ (2005). What Shifts? Thresholds, Standards, or Alternatives?. In Gerhard Preyer \& Georg Peter (eds.), Contextualism in Philosophy: Knowledge, Meaning, and Truth. Oxford University Press: 115-30.

Stalnaker, Robert. (1974). Pragmatic Presuppositions. In Milton Munitz \& Peter Unger (eds.), Semantics and Philosophy. New York: New York University Press: 197-214. (2002). Common Ground. Linguistics and Philosophy 25 (5-6): 701-21.

Stanley, Jason. (2005). Knowledge and Practical Interests. Oxford: Oxford University Press. 